Europe's Journal of Psychology 3/2009, pp. 56-81

www.ejop.org

\title{
Hitchcock's Conscious Use of Freud's Unconscious
}

\section{Constantine Sandis}

Oxford Brookes University and NYU in London

\begin{abstract}
This paper explores Alfred Hitchcock's use of Freudian psychoanalysis in a number of his films, with particular emphasis on Spellbound (1945), Psycho (1960), and Marnie (1964). I argue that the films (and related primary source material) demonstrate that Hitchcock was largely unconvinced of the validity of psychoanalytic theory and practice which he frequently mocked, both on-screen and off. Nonetheless, he greatly appreciated the magnetism of the psychoanalytic process and general charm of Freud's conceptual world. It is for this reason that he kept returning to Freudian aesthetics throughout his cinematic career. Indeed, understanding how Hitch came to master this love/hate relationship is the key to understanding when and why the films succeed as well as where and how they fail. The paper ends with an analogy between Hitchcock's attitude to Freud and that of Ludwig Wittgenstein with the further aim of evaluating some of Freud's most significant ideas.
\end{abstract}

Keywords: Freud, Hitchcock, Wittgenstein, psychoanalysis, unconscious, dreams, guilt, repression, divided mind, scientific validity.

'The stupid idiots! As if I don't know what I'm doing. My technique is serious. I am consciously aware of what I am doing in all my work'

Alfred Hitchcock (upon being told that The New Yorker magazine has described an aspect of Psycho as 'unconscious') 


\section{Screen Test: From Couch to Celluloid}

Sure, some of the Freud stuff is "cheesy", but it still "pulls".

C.D. Strother, reviewer on amazon.com

There isn't a shadow of a doubt that the master of suspense knew a thing or two about psychology. Indeed, it is inconceivable that a cinema director with the ability to trick and treat an audience the way Hitchcock did could remain a stranger to the human psyche.

Hitchcock's grasp of human psychology was chiefly - if not entirely - intuitive. He did not embrace any specific psychological theory and his knowledge of both the academic discipline and the medical practice it eventually gave rise to (a practice which he often expressed a strong distaste for) was fairly limited. Preferring to read both fictional and factual accounts of thefts and murders he often 'fell in love with', Hitch gained most of his psychological insight by combining his indirect study of criminal lives with the observation of the day to day behavior of those around him and some good old-fashioned introspection.

Still, as Patrick McGilligan notes in his biography A Life in Darkness and Light, 'the director wasn't unfamiliar with Freud's writings, having first browsed them in the 1920s' and indeed 'was more than capable of expounding... on symbols... and artefacts' ', Freud being 'a hot topic at Cromwell Rd'2 while Hitch was filming The 39 Steps. Despite the fact that Hitchcock 'didn't take the subconscious too seriously, and in his private life studiously avoided doctors of the mind'3, he clearly must have found something valuable in what he read. Many of his films including The 39 Steps (1935), Notorious (1946), Vertigo (1958), North by Northwest (1959), and The Birds (1963) hint at the Freudian4, while the central plots of three are explicitly couched in psychoanalytic terms. These are 1945's Spellbound, 1960's Psycho, and 1964's Marnie (from here onwards collectively referred to as the Freudian Trilogy, which is not to suggest that Hitchcock ever conceived of them as such).

\footnotetext{
1 McGilligan (2003: 355).

2 lbid: 173.

3 lbid: 355.

4 Vertigo is particularly fraught with Freudian imagery, the rather ludicrous plot (parodied in Mel Brooks' High Anxiety) hanging upon a tenuous connection between the protagonist's acrophobia and repressed guilt.
} 
So why did Hitch return to Freud time and time again if he didn't take his work all that seriously? The answer to the mystery, I suspect, is that he was drawn to Freud's theories because he found them charming rather than theoretically persuasive. Part of the appeal that made Freud so contagiously popular among literary and artistic circles is the sheer simplicity of his theories. The basic principles of Freud's psychological theory are easy to grasp and one does not need an iota of science or philosophy to make sense of them (if anything such knowledge complicates the task). Freud, like Nietzsche before him, suspects that we rarely act for the reasons that we think. Both theories were to become enormously influential; but whereas Nietzsche ultimately characterises all drives as manifestations of the ephemeral (and much misunderstood) will-to-power, Freud's focus on sex and death is more concrete, memorable, and saucy.

Even the most technical of Freud's terms resemble ordinary figures of speech. It is no accident that a conscious selection of bespoke terms such as 'defense mechanism' and 'repressed guilt', each carefully tailored (in both the original German and their subsequent translations) to make us feel at home without having opened a single psychology textbook ${ }^{5}$.

This aspect to Freud's psychological insight was the one that Hitchcock (a maker of popular films after all) could best relate to. No stranger to Freud's train of thought he understood why, in contrast to the alienating jargon of most scientists and academics, Freud's choice of vocabulary helped to ensure his rise to popularity. Witnessing how swiftly psychoanalysis was permeating the arts and predicting that it would maintain a lasting presence in the mind of society at large, Hitchcock too wanted a piece of the irrational action.

He didn't quite get there first though. Compton Bennett's The Seventh Veil produced independently for less than $£ 100,000$ (compared to Spellbound's estimated $\$ 1.7$ million) on a rapid shooting schedule - beat him by a fraction in the photo finish6. Scripted by Sydney and Muriel Box, the film largely consists of a series of flashbacks in which the protagonist Francesca Cunningham removes seven

\footnotetext{
${ }^{5}$ Freud was by no means averse to employing jargon (some of which appears further below) when the context called for it. He always held control of its aesthetic power though, arguably so much so that it caused him to overlook some of its semantic significance.

6 The Seventh Veil premiered in the UK on the $18^{\text {th }}$ of October 1945 and in the US on Christmas Day, reaching theatres on the continent throughout the new year. Though Spellbound had previewed as early as September 1944 (before The Seventh Veil had even began shooting) it did not premier until October 31 1945, in New York (and was released December $28^{\text {th }}$ in the rest of the US, with openings in Europe dispersed throughout the rest of the 40 s and into the early 50s). Sources: www.tcm.com, www.imdb.com, \& www.criterion.com.
} 
memory-veils under hypnotherapy. It was the biggest British box-office success of 1946 and in anticipation of its 2009 DVD release the British Film Institute announced that it remains the tenth most successful UK hit in terms of box office ticket numbers ${ }^{7}$, despite the fact that it's influence remains negligible compared to that of Hitch's Freudian Trilogy (for reasons that should become clear by the end of this essay).

To this day, then, psychoanalysis sells and everyone is buying. As one of the most popular of the Psychology textbooks that Hitchcock never read puts it:

Whatever its shortcomings as a scientific theory, the psychoanalytic account of personality remains the most comprehensive, far-reaching, and influential theory of personality ever created. Its impact extends well beyond psychology, influencing the social sciences, the humanities, the arts, and society generally...many of its ideas have been absorbed into the mainstream of psychological thinking. ${ }^{8}$

It is in acknowledgement of this magnetic power, as opposed to any theoretical validity, that attracted Hitchcock to Freud's work. Put to the test of Hitchcock's silver screen, however, the resulting Freudian picture of human personality disappoints: in stark contrast to Hitch's other films, the motivations of the characters are implausible, the explanations of their actions unconvincing. The fault is not in Hitchcock's understanding but with Freud's own theories. Hitch is conscious of this and ultimately overcomes it, or so I shall claim. But first some Freudian basics.

\footnotetext{
7 In 1947 The Seventh Veil won the award for best original screenplay. By contrast Spellbound scriptwriters Angus MacPhail and Ben Hecht did not receive a nomination when in 1946 (the film being a US production) composer Miklós Rózsa won the film the Academy Award for best music score. Spellbound was also nominated for best actor in supporting role (world-famous Russian playwright Michael Chekhov for his memorable portrayal of Dr. Burlov), best special effects (largely centered around Dali's famous dream sequence), best black and white cinematography, best director, and best picture (op. cit).

8 Atkinson et. al (1985: 511 ); cf. Godfrey-Smith (2003:72).
} 


\section{Doing the Unconscious: The Divided Self}

Like Freud, Hitchcock diagnosed the discontents that chafe and rankle beneath the decorum of civilization.

Peter Conrad, The Hitchcock Murders 9

Nowadays we readily associate over a dozen psychological notions and concepts with Freud. A couple I mentioned above, others include wish fulfillment, libido theory, neurosis, hysteria, psychosis, the Oedipus complex, the interpretation of jokes, psychic reality, guilt transference, and displacement theory. Despite their prima facie diversity these all emerge from a single underlying theory which grounds and unifies them into a coherent whole.

At its most general level, Freud's theory of the unconscious states that a large subset of our memories, emotions, fears, impulses, thoughts, and desires are inaccessible to our consciousness, being instead assigned to our so-called subconscious. The term purportedly refers to a blocked part of the mind that cannot be reached through ordinary introspection ${ }^{10}$. Accordingly, its contents are said to reside in our subconscious when we have repressed them, thus forcing them to steer towards our dreams and behavior through poorly lit backstreets. The psychoanalyst's job, then, is to police the area and provide safe escort for all. Without such protection abnormal behavior (which differs from normal behavior only in degree and not in kind) increases to the point of mental illness. Psychoanalytic therapy takes various forms including hypnosis, free association, and the interpretation of dreams, all of which play central roles in the Freudian Trilogy. To understand their explanatory force, however, we need to dig a little deeper into the Freudian of personality.

Freud may have been clumsy to equate the human self with the human mind, but he did so with great precision, dividing it into three conflicting parts: the id, the ego,

\footnotetext{
9 Conrad (2001:xiii).

10 Of course Freud does not claim that every belief, feeling, memory etc. which we are not currently conscious of resides in the unconscious. There are elements of our psychology (arguably most of them) which although we may not be consciously aware of all the time, we could nonetheless easily turn our consciousness towards should we so choose. Freud calls such mental phenomena 'preconscious' because they are readily available should we decide to turn our attention to them. Unconscious psychological phenomena, by contrast, we cannot recognise by simply turning our consciousness towards them.
} 
and the superego ${ }^{11}$. The id is chiefly comprised of innate biological drives, instincts, and dispositions, as well as the wishes, feelings, and memories of past experiences that are typically associated with them. By contrast the ego, which we develop as young children, is made up of those mental phenomena relating to whatever environmental considerations constrain the id (Freud calls these the 'reality principle'), for example, the id's basic hunger drive is constrained by beliefs (in the ego) about what food is available where. Finally, the superego contains our internalized representations of social values and morals and our related moral judgments. All of the id is unconscious while most of the ego is conscious. A great deal of the superego and some of the ago are preconscious, though occasionally some of its contents will reside in the unconscious (depending on their relation with the id).

Freud frequently compared the human mind to an iceberg, of which only a tiny part (representing conscious experience) appears above the surface of the water (possibly representing human perception). Below the surface, however, lies a much larger, darker part of the iceberg, representing the unconscious (see Fig. 1 below).

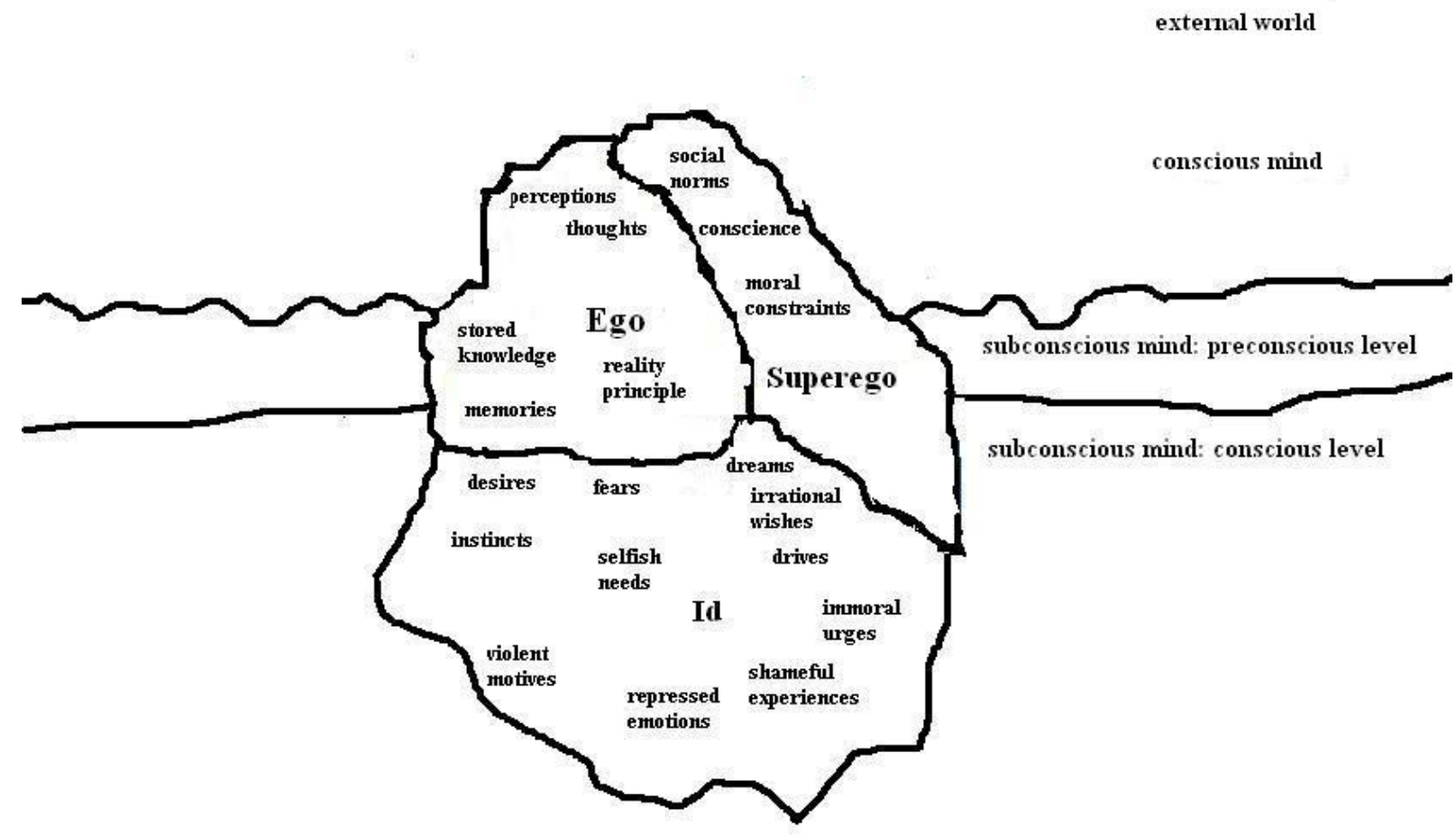

11 "Ich" had been typically translated as "I" and "Es" as "It" until the publication of the first volumes of the Standard Edition of Freud in the 1950s whence they became known as "Ego" and "Id" respectively, cf. Dexter (2007: 143ff). 
The id is the source of all basic drives and instincts, while the superego is governed by the moral constraints which govern our conscience (and, as we can see in the diagram, Freud thought we were conscious of some of these, but not most. Finally the ego's job is to settle the conflict between the superego and the id (that are often at odds with each other), and in so doing provide us with a sense of self. Sometimes it resolves conflict in favor of the id, and other times in favor of the ego, but it never satisfies either fully. Finally between the conscious and the unconscious mind, Freud believed there to be what he called a 'preconscious' which includes believes, memories, and desires that we are not currently conscious of but which we can easily be triggered or otherwise brought to our attention without the need for psychoanalysis. Symbolically, this might be just below sea-level, easily perceived from above.

Like Freud, Hitchcock time and time again presents us with the ordinary and familiar before revealing a twisted picture of what lies beneath (a picture we know is coming but whose precise shape is always novel). We cannot be certain that Hitchcock ever came across the iceberg metaphor, but he would have undoubtedly found it inspiring. Hitch frequently chose to present us with leading ladies that appear to be cold as ice, only to reveal that once their exterior melts, an abundance of repressed thoughts and desires rises to the surface.

A recurring feature in all his work, this technique is elevated to new proportions within the Freudian Trilogy. Consider Marnie, for example. Her appearance and behavior, in particular towards men, are so chilling that Mark Rutland (the character played by Sean Connery) senses that something is wrong underneath. It is as if a mask has been built to fend off any offenders who might potentially want to uncover what lies beneath. In a bid to repress an id that is as dark as Marnie's, the ego and superego build a particularly strong bright shield to cover it. The ego does this by representing Marnie as a hard-shelled thief who will not let the feelings of others get in the way, while the superego identifies itself with a man-hating morality, and a general distrust of man's animal instincts.

To elaborate, Marnie's id is formed by basic drives which have somehow been transformed by a traumatic (shame-inducing) experience which can only be recalled through psychoanalysis. This evokes a fear of sex, coupled with a violent disposition towards men (particularly men she might be said to be attracted to, for they represent a greater danger). On a Freudian analysis, at the start of she is not conscious of any of these things when the film begins, but only of whatever thoughts and perceptions lie at the tip of her consciousness. Marnie believe she is in control of 
her actions, taking herself to base these upon the beliefs, perceptions, and moral principles which she is conscious of. In material reality, however, her behavior is governed by the fears, motives, and experiences which lie at the bottom of a deep mental ocean. As the film progresses Mark gradually lowers her the sea level until the bedrock is eventually uncovered.

We witness a similar process in Spellbound: Constance Peterson's clinical exterior (ironically) thaws in direct proportion to her successfully recovering memories of snow from John Ballantine's subconscious. Her exterior helps the ego and superego to suppress the id but also betrays that something is wrong underneath. It is the job of psychoanalysts to look out for such signs yet they frequently report that fear of being unmasked inevitably leads to a distrust of psychoanalysis. So it is that in Spellbound the patient Miss Carmichael mocks it:

This whole thing is ridiculous...psychoanalysis, it blows the pants of me. Lying there on the couch like some dreary nitwit telling all. You Don't really expect to get anywhere listening to me babbling about my idiotic childhood, really...I see it's my subconscious putting up a fight... it doesn't want be cured...you and your drooling science...l detest you...you and your nickels worth of nothing.

Ballantine likewise declares that he doesn't believe in dreams: 'that Freud stuff is a lot of hooey' and in Marnie the leading lady (who turns out to be lead, by her subconscious) implies that psychoanalysis is both primitive and offensive: 'me Jane you Freud?' Hitchcock knows that large parts of the audience - people like himself will be sceptical, but also recognizes that a great part of the charm of psychoanalytic theory is that it has constructed itself in such a way that these sorts of objections will only be seen as further confirmation of its validity viz. unconscious resistance to what psychoanalysis would reveal. In the case of Marnie and Constance this would also explain why it takes a Rutland or Ballantine (outsiders whose personalities are in no competition with the ids of Marnie and Peterson) to cure them.

But if even an intelligible, well-articulated, denial of the value of psychoanalysis is taken to confirm its truth we may legitimately wonder whether any possible evidence could ever count against it. The philosopher Karl Popper maintained that nothing could, thereby concluding that psychoanalysis was not a science since all scientific theory must in principle be falsifiable (cf. Popper 1963). The extent to which his objection succeeds depends on whether we can conceive of possible evidence 
which the Freudian would take to count against psychoanalytic theory ${ }^{12}$.Popper was quick to point out, not having any bona fide scientific credentials does not rob a theory of all possible values. Ideologies such as Marxism, Popper thought, had nonscientific value, and perhaps the same could be said of psychoanalysis.

Hitch would not have expressed his own reservations in so analytic a fashion, still it would not be wrong to attribute to him the view that while psychoanalytic theory is not much of a science, it nonetheless a world of value.

\section{In Dreams: Spellbound by Guilt}

Film should be stronger than reason

Alfred Hitchcock

It was arguably a historical accident that triggered Hitch's cinematographic interest in psychoanalysis. In the early 40s, film producer David O. Selznick found himself suffering from depression and began seeing a therapist Mary Romm. Within a year he had asked Hitchcock to make a film based on this personal experience with psychoanalysis, which had been entirely positive. Hitchcock agreed and Romm was hired as his 'psychiatric' advisor (cf. Leff 2002). Anecdotal evidence suggests that he ignored her advice in how therapy works, responding on at least one occasion with the words: 'My dear, it's only a movie. Don't take it too seriously'.

The film in question, Spellbound, was based loosely on 'Francis Beeding ${ }^{13}$ 's' novel The House of Dr. Edwardes (Hitchcock's preferred title for the film, alongside Hidden Impulse ${ }^{14}$ ). There is little doubt that Hitch primarily saw it as a vehicle for conveying the charm of psychoanalysis by 'giving cinematic life to the dreams that help unravel the amnesiac's identity' ${ }^{15}$. So much is revealed in his interviews with famous French filmmaker François Truffaut:

12 Prior to Popper, the logical positivists had argued that an expression or theory was only meaningful if its truth could be verified. For some positivists, this entailed conclusive establishment through experience. Others, such as A.J. Ayer, understood verification in terms of mere probability. While there are plenty of reasons to reject the Verification Principle on either understanding (for one it is by its own lights itself meaningless) it is worth questioning the sense in and extent to which certain data might be thought to verify psychoanalytic theory.

${ }^{13}$ A pseudonym for John Leslie Palmer and Hilary Aldan St George Sanders.

14 Leff (2002).

15 Truffaut (1967: 355). 
F.T: I saw Spellbound again recently and I must admit that I didn't care very much for the scenario.

A.H.: Well, it's just another manhunt story wrapped up in pseudopsychoanalysis...we tried to use a logical approach to the man's adventure.

$[\ldots]$

F.T.: I hope you won't be offended but I must say I found the picture something of a disappointment.

A.H.: Not at all. The whole thing's too complicated, and I found the explanations towards the end very confusing. ${ }^{16}$

This last point, in conjunction with the reference to pseudo-psychoanalysis confirms that Hitchcock was not remotely interested with the scientific details of the explanation. Indeed, the film is said to fail because, in spite of everything, the details of explanation remain too complicated. Consider the film's enigmatic dream sequence, designed by Salvador Dalí17, as a test case since, from a cinematic point of view, the interpretation of dreams was obvious territory for Hitch to explore.

According to Freud, all dreams represent wish fulfillment, being manifestations of hidden, unconscious, fear, conflicts, desires, and impulses. These all strive to express themselves in our sleep, when our conscious defenses are at their weakest. In dreams, Freud claims, the unconscious appears in a disguised form. Thus every manifest content (what the dream is directly about) is supplemented by a latent content, constituted by the unconscious conflict represented in disguised ways. In Dr. Burlov's words:

Now here's where dreams come in. They tell you what you are trying to hide, but they tell it to you all mixed up like pieces of a puzzle that don't fit. The problem of the analyst is this: to examine this puzzle, and put the pieces together in the right place and figure out what the devil you are trying to say to yourself.

In the case of Edwardes (aka John Ballantine) the pieces include a gambling house, a large pair of scissors cutting drapes with eyes painted on them in half, a semi-clad

\footnotetext{
$16 \mathrm{lbid}(165 \mathrm{ff})$.

17 Cf. Spoto (1983) and Leff (2002) for two examples of the diverse accounts of Dalí's presence, the dream sequences that ended up on the cutting room floor, and the reasons why Hitchcock, among others, found them distasteful.
} 
woman (who, he reports, looks like Constance) that is kissing everybody, the proprietor of the casino has a blank face, Edwardes playing cards with a man with a beard (he deals him the 7 of clubs, the man then claims he's got 21 but his cards are blank when he turns them over ), a man in a mask drops a misshapen wheel on a sloping roof, a man with a beard falls, Edwardes is chased by wings to the bottom of a hill and then escapes. So described, these pieces give us the dreams manifest content.

Dr. Burlov and Constance (who goes to Dr. Murchinson for help) shift the pieces around until Berlov found an interpretation which he takes to represent the dream's latent content, and ultimately reveal what Edwardes' subconscious was trying to tell him: the gambling house represents Green Manors and its inmates; the proprietor is the head of the asylum Dr. Murchison, the bearded man is presumably the real Dr. Edwardes; the blackjack game ('21') and the 7 of clubs 'represent' the 21 Club which Ballantine and Edwardes had once been to, the blank cards a sign of Edwardes' denial; the eyes on the curtain represent the guards of the asylum and Ballantine's cutting them is an expression of his wish to escape; the girl kissing everybody is Constance who he is in love with, the man behind the mask is the proprietor trying to hide his identity; the wheel represents a revolver and the sloping roof the slope at Angel Valley; the wings stand for his being chased (by Constance who he sees as an angel) but they also refer to Gabriel Valley, the ski resort where the murder took place, represented in the dream by the bottom of the hill. It is in this latent content that the real meaning of the dream is to be found. Even deeper in John Ballantine's lies the explanation for why all these repressed memories and feelings have been blocked from his consciousness: when he was a boy he accidentally killed his brother while sliding down a snowy slope, the repressed memory of this event is re-awakened when he witnesses the murder which Murchinson commits on the slopes of the ski resort thus triggering a transfer of guilt from the death of his brother to the death of the real Dr. Edwardes.

The memories are finally unlocked once Constance takes John back to the scene of the crime and Ballantine is eventually revealed by psychoanalysis to be an imposter suffering from amnesia, tormented by a dark secret in his past. The connection between the latent and blatant 'meanings' of the dream are drawn up from facts about the patient's unusual behavior combined with known facts about his biography such as the fact that Ballantine cannot bear to see dark lines on white surfaces (be it the fork lines on the tablecloth, or the pattern on Constance's robe and the duvet in the hotel room), suggesting that Ballantine was traumatized by an episode involving lines on a white surface. 
This hardly amounts to evidence for the radical dream symbolism that we are subsequently subjected to in the movie (for a detailed criticism of Freud's method of dream interpretation see $\S 6$ below). Dr. Mary Romm was there to advise both Hitchcock and Dalí on how to make the symbolism as convincing as possible on a theoretical level, however both artists believed (rightly) that visual symbols need not be theoretically valid in order to successfully perform their function which was, effectively, to associate ideas in such a way that they generate the kind of clues which neither give the game away nor leave viewers feeling cheated (the blackjack game is a successful case in point). Indeed Hitch seems to have been of the opinion that if any symbolism was theoretically plausible at all (which he greatly doubted) It would lack aesthetic pull and take away from the thrill of the picture which relies on emotional impulses rather than rational understanding (a point he explicitly makes in relation to Psycho, see $\S 6$ below) ${ }^{18}$.

Hitchcock did not want the theory to get in the way of the experience, as it ultimately did. His rightful concern (with both the Ramm-infuenced screenplay and Dalí's ideas) was that the sheer complexity of it all, which strips the overarching theory of any cinematic elegance or pull it may have otherwise had. Could this be the reason why in the end it is love, not psychotherapy alone, that heals Ballantine (cf. Brill 2002)? Either way, it would explain why his disagreements with Dalí and Romm (see above, esp. fn. 17) related to aesthetic and not explanatory concerns. When over half the dream-sequence was abandoned, Hitchcock was not in the least worried about what the dream's 'meaning' would now be reduced to.

To recapitulate, let us return to the film's opening. It begins with a partial quotation from Shakespeare's Julius Caesar:

The fault...is not in our stars, but in ourselves...

The rather general sentiment expressed her is one that Freud embraced, still, one does not need to be Freudian to agree with it (for one, Jung, Klein, and Jaspers would agree with it too). It is also worth looking at the full original quotation (from Act I, Scene II):

${ }^{18}$ Hitchcock - though possibly not Dalí - would have detested most of what currently goes on under the 'film-studies' umbrella, not least psychoanalytic studies of his own work. It is hard to say whether or not commercial interests would have affected his public attitude towards them. 
Men at some time are masters of their fates: The fault, Dear Brutus, is not in our stars, but in ourselves, that we are underlings.

Now why should the reference to being underlings (i.e. subordinates) be removed? A possible answer (I have no proof here) is that Hitch did so consciously because he rejected this most crucial aspect of Freud's theory, as illustrated by one of his best known passages:

In the course of centuries the naive self-love of men has had to submit to two major blows at the hands of science. The first was when they learnt that our earth was not the centre of the universe but only a tiny fragment of a cosmic system of scarcely imaginable vastness. .. The second blow fell when biological research destroyed man's supposedly privileged place in creation and proved his descent from the animal kingdom and his ineradicable animal nature. ..But human megalomania will have suffered its third and most wounding blow from the psychological research of the present time which seeks to prove to the ego that it is not even master in its own house, but must content itself with scanty information of what is going on unconsciously in its mind ${ }^{19}$.

Some support for the view that Hitch was trying to distance himself from the final claim made above may be found in the caption which immediately follows the Shakespeare quotation in the film:

Our story deals with psychoanalysis, the method by which modern science treats the emotional problems of the sane. The analyst seeks only to induce the patient to talk about his hidden problems, to open the locked doors of his mind. Once the complexes that have been disturbing the patient are uncovered and interpreted, the illness and confusion disappear... and the devils of unreason are driven from the human soul.

On the face of it this has a classic psychoanalytic feel and appears mundane enough to pass us by without further consideration, yet it may well disguise an antiFreudian code. For one, the only thing which the analyst seeks to do is, effectively, to pry into the patient's mind. And let us not forget that in Spellbound it is the doctors who are deceived - indeed spellbound - by the patients.

19 Freud (1953-74, Vol. XVI: 284-5). 
Equally striking is the choice of the word 'sane' (as opposed to 'insane' or at the very least 'neurotic'). Compare this to the following (typical) passage from Freud in which he suggests that no human being is fully sane:

If you look at the matter from a theoretical point of view and ignore this question of degree you can very well say that we are all ill i.e. neurotic; for the conditions required for symptom-formation are demonstrable also in normal persons ${ }^{20}$.

Could it be that that the joke was on Freud, Selznik, and Romm? As we are about to seem Hitch's treatment of both Spellbound and Marnie would certainly support this reading. Either way, Spellbound succeeds only partially and despite the complex (and at times implausible) motivations of the characters. By the time he shot his next Freudian piece, Hitch had learned his lesson.

\section{Dial P for Psycho-analysis}

I suppose it must have all started when I was in my mother's arms at the age of six months and she said to me: 'boo' and scared the something out of me, you know.

Alfred Hitchcock, in interview21

Scripted by Joseph Stefano (from the novel by Robert Bloch), Psycho is chiefly remembered for its notorious shower scene rather than for any association with psychoanalysis, yet it is the most Freudian of all Hitchcock's films. The parallel between Lila Crane's exploration of the Bates house and our gradual exploration of the various rooms (departments) in Bate's divided mind alone confirms this.

Hitch's own assessment of the granddaddy of horror films was that its success was largely due to its implausibility. In conversation with François Truffaut he says:

If Psycho had been intended as a serious picture, it would have been shown as a clinical case with no mystery or suspense. The material would have been used as the documentation of a case history. We've already mentioned that total plausibility and authenticity merely add up to a

\footnotetext{
20 From Introductory Lectures on Psychoanalysis (1915; reprinted in Freud 1953-74).

${ }_{21}$ Robinson (1960).
} 
documentary. In the mystery and suspense genre, a tongue-in-cheek approach is indispensable. ${ }^{22}$

In contrast to Spellbound, which fails because - for all its beautiful cinematography the documentary-like explanation is horrendously complex, Psycho is said to succeed because the Bate's motivation is not put forward as a serious hypothesis but, instead, as something humorous, and at best only partially plausible. 'I am aware that I am equipped with what other people might have called a fiendish sense of humor'23, Hitchcock would volunteer when questioned about the final sequence in Psycho:

You have to remember that Psycho is a film made with quite a sense of amusement on my part. To me it's a fun picture The process through which we take the audience, you see, it's rather like taking them through the haunted house at the fairground, you know. After all it stands to reason that of one were seriously doing the Psycho story, it would be a case history. You would never present it in forms of mystery or the juxtaposition of characters, as they were placed in the film. They were all designed in a certain way to create this audience emotion. Probably the real Psycho story wouldn't have been emotional at all; it would've been terribly clinical. ${ }^{24}$

In certain obvious ways, the Freudian element in Psycho is reminiscent of that in Spellbound. First of all we have the repressed memory of a traumatic incident causing a transfer of guilt (manifested, on this occasion, as an oedipal complex). This in turn leads to a partial loss of 'the self' and a strong sense of identification with the victim (in Spellbound Ballantine takes on Edwardes' identity; in Psycho Bates takes that of his mother). Psycho gets away with it because it strikes the right balance between simplicity and humour. Within film, theory works best when kept relatively simple, even when this is at the expense of certain kinds of authenticity. It was the inability to fully grasp this point that caused The Seventh Veil - and to a lesser degree Spellbound 25 - to suffer from the clinicality Hitchcock warns against above.

22 Truffaut (1967:202).

23 Rebello (1998: 20).

${ }^{24}$ Gotlieb (2003: 47-8). Hitch is here referring to the real-life case of Ed Gein who kept his dead mother's room in Wisconsin inviolate and untouched, and allegedly used to dress up in her 'breasts and skins' in which he murdered about a dozen women (with, apparently, no subsequent memory of having committed any of the crimes).

25 Lesser because, like Psycho, it is redemmed by humour. 
Psycho, like so many of Hitch's films, is not to be conceived as a whodunit but, rather, as a macabre way of satisfying the emotional needs of his audience. The real suspense is about what the 'cinematic suspense' will next be about. On Hitchcock's view, it doesn't actually matter what the MacGuffin is. So long as it is sufficiently important to the characters to motivate the action, the audience doesn't need to care about it at all (cf. Gottlieb 2002: 48). In the master's own words:

I've never dealt with whodunits...they're simply clever puzzles, aren't they? They're intellectual rather than emotional, and emotion is the only thing that keeps my audience interested. I prefer suspense rather than surprise something the average man can identify with. The audience can't identify with detectives; they're not part of his everyday life. ${ }^{26}$

Still, we might think that the film is not so entirely removed from this genre that there is no question of who did it. We would feel cheated, for example, if all the clues that might enable us to guess were not in place. Such was Truffaut's reaction to the original book:

I've read the novel from which Psycho was taken, and one of the things that bothered me is that it cheats. For instance, there are passages like this: "Norman sat down beside his mother and they began a conversation." Now, since she doesn't exist, that's obviously misleading, whereas the film narration is rigorously worked out to eliminate these discrepancies .27

The film version is more honest and even includes a shot of Bates swinging his hips as he climbs up the stairs. It only lasts for a few frames but it is sufficient for an observant viewer to infer the film's denovement from it. As Hitch put it, 'the basic clue was in the feminine nature of the character altogether'. ${ }^{28}$ He might have also added Bates' interest in taxidermy.

Nonetheless, we do remain somewhat cheated by the fact that the voice of Bates' mother is not that of Anthony Perkins but a 'spliced and blended' recording of one

\footnotetext{
26 Rebello (1998: Ch. 3). In a 1947 Hollywood press conference Hitchcock stated: 'I aim to provide the public with beneficial shocks, Civilization has become so protective that we're no longer able to get our goose bumps instinctively. The only way to remove the numbness and revive our moral equilibrium is to use artificial means to bring about the shock. The best way to achieve that, it seems to me, is through a movie' cf. Truffaut (1967:202).

27 Ibid: 268.

28 Gottlieb (2003:48).
} 
male and two female voices ${ }^{29}$. For Hitch, however, this is all part of the playfulness which makes the film work:

Psycho has a very interesting construction and that game with the audience was fascinating. I was directing the viewers. You might say I was playing them, like an organ. ${ }^{30}$

Gus van Sant's shot-for-shot 1998 duplicate, by contrast, was doomed to fail in this respect from the outset ${ }^{31}$.

\section{Marnie: Murder Most Unconscious}

Old Pond. Frog jumps in.

Repressed sexual desire,

Clearly Oedipal.

David Bader, 'Sigmund Freud's The Interpretation of Dreams in Haiku's2

Gosh can you imagine anyone resisting Sean Connery? That ought to tell you how troubled she was.

Dianne Foster, reviewer on amazon.com

It took only four years for Hitchcock to return to the theme of psychoanalysis in 1964's Marnie, with a 'final script' by Jay Presson Allen (the third writer Hitch employed to script Winston Graham's 1961 novel of the same name) ${ }^{33}$. The parallels between this last film of the trilogy and the first are striking: a dream ripe for interpretation, an emotional trigger (the color red, which plays a similar role to the dark lines on white surfaces in spellbound), and a neurotic protagonist who is suspicious of psychoanalysis yet comes to be 'cured' after being forced to relive a past traumatic experience ${ }^{34}$. Hitch still saw cinematic value in Freud.

\footnotetext{
29 Paul Jasmin, Jeanette Nolan, and Virginia Gregg.

30 Truffaut (1967: 269).

31 In this respect the 1983-1990 pre/sequels (which form no part of Hitchcock's oeuvre) fair better.

32 Badder (2005).

33 Many critics have attacked Marnie on purely cinematic grounds, questioning, for example, the painted backgrounds, atmospheric thunderstorms, red suffusions etc. I shall not concern myself with such criticisms here, save to refer readers to the admirable and coherent defense of the expressionist devices of Marnie's realism in Wood (2002: Chs. 8 \& 19).

34 Mark Rutland and Lil Mainwarin (Mark's sister-in-law) may additionally be viewed as representing, respectively, Marnie's Superego and Id. Lil's instincts are typically channelled into
} 
The term neurosis, derived from the Greek words neuron (nerve) and osis (abnormal condition), was coined by the Scottish physician William Cullem (1710-1790) to refer to 'disorders of sense and motion' whose cause lies in a 'general affection of the nervous system'. In post-Freudian psychology it is typically used to refer to any mental disorder which, while causing anxiety and distress, does not interfere with a person's ability to reason and function. So conceived, both John Ballantine and Marnie exhibit clear signs of neurosis, in contrast to Norman Bates' psychosis, a more severe pathological condition under which the patient becomes incapable of functioning normally (hence the term psychopath, abbreviated to the pejorative 'psycho').

According to Freud, neurosis is an ineffectual coping strategy/defence mechanism of the ego, caused by repressed memories and emotions and triggered by events which resemble them in some way. Ultimately, it results in one or more phobias (uncontrollable and irrational fears) such as vertigo (see fn. 4 above) or the fear of red (which Marnie shares with Ballantine). The neurosis itself - a defence mechanism of which phobias are but one resulting aspect - may also take many forms: anxiety, hysteria, obsessive-compulsion disorder, frenzy, pyromania, etc. Guilt, too, plays a prominent role: Ballantine feels guilty for a murder he didn't commit (a nice twist on Hitchcock's favourite theme of an innocent man accused), Bates both blames his mother for the murders he committed and wants to be her because he cannot reconcile himself with the guilt of having killed her, and Marnie represses the guilty memory of having killed the young sailor.

In Spellbound Ballantine's neurosis involves a fixation on the identity of a person whose death he feels guilty about (though not in the psychotic way in which Bates takes on the identity of his mother). Marnie's neurosis, by contrast, manifests itself in a combination of man hatred and kleptomania. The latter is to be analysed in terms of an association she makes between the notion of earning and the painful incident she is trying to repress. She steals from men and sends back the money to her mother (whose past profession lies at the heart of her neurosis)

At first sight, Marnie appears to have a happy ending: the protagonist is cured by psychoanalysis and in love with Mark Rutland (despite the deep implausibility of the

her consciousness through her love for her horse Forio which she puts to death herself. In Graham's novel Marnie merely watches as Forio is shot by someone else; there is no Lil character. Instead, Mark has a cousin (Terry) with whom he competes for Marnie's affections. 
vile form of her breakthrough $\left.{ }^{35}\right)$. But things are not so simple. As Robin Wood has pointed out, Marnie is not really cured at the end of the film, though she has 'confronted and to an extent transcended her trauma'36. The clue, Wood tells us, lies in her tentative last line 'Oh, Mark, I don't want to go to prison. I'd rather come home with you'. A close comparison between her description of her 'reclaimed memory' and the images used to accompany it reveals that she misremembers certain key facts. 'I hit him with a stick' we hear her say as we watch her hitting him with a large fire-iron. She also claims that the sailor hit her mother, yet all we see is her mother hitting him: 'only the spectator has access to the whole truth, while Marnie's account of it is subject to distortions and inaccuracies'. ${ }^{37}$ This account of Marnie's end shares close parallels with the interpretation of Spellbound's opening favoured above. It would seem that Hitchcock has cheated Freud for the third time. This is not the work of a man who strongly believes in the curing powers of psychoanalysis.

\section{The Trouble with Freud}

I have a vague recollection of being scared by a policeman ...I think that when I was probably about 4 or 5 years of age being sent with a note at the local police station and being shut in a cell as a punishment for some... mishap or... I think I don't even know what it was for, I was probably unjustly incarcerated at the time. But you see the psychiatrist will always tell you if you have a fear that is rooted in you and comes from something in your childhood, the moment you can go back to it and release it all is well. It doesn't apply to me, l'm still scared of policemen.

Alfred Hitchcock in interview 38

Frequently asked about his obsession with the theme of innocent men accused, Hitchcock would volunteer constantly mutating versions of the above - most likely apocryphal - story. The great director intuitively understood that the implication of a

35 This is much discussed in the literature on Marnie. A good place to start is Wood (2002: Chs. 8 \& 19). 36Wood (2002:404).

37 Ibid: 401.Towards the end of the novel the film is based on, Rutland exclaims 'It's all nonsense, Marnie, all these barriers that you're putting up. Nothing's in the blood, nothing's in the upbringing, nothing happened at Sangerford that we can't throw away forever if you want to try, if you've got courage and some love. Because they're so much stronger than all these shabby ghosts. If you once find your way through the first thickets, there's nothing that we can't do together.' Hitch, by contrast, is less optimistic about the possibility of ridding ourselves from any ghosts of the subconscious.

38 Robinson (1960). 
traumatic experience lodging a lifelong fear in his subconscious would fascinate and excite his audience.

As we have seen, Hitch put little faith in the scientific validity of psychoanalytic theory, a stance which accords not only with the views of philosophers such as Karl Popper (see $\S 2$ above) but with the scientific community at large ${ }^{39}$. A related set of philosophical objects to the Freudian account of human personality has been put forth by Ludwig Wittgenstein, who accused Freud of meaninglessly ascribing judgments, wishes, beliefs, and intentions to subparts of our personality which are not conscious (and function as purely causal mechanisms).

Upon first reading Freud, Wittgenstein claimed to have been fascinated by him, to the point of considering himself 'a disciple'. He soon changed his mind though, becoming increasingly suspicious of Freud's use (or rather misuse) of certain psychological concepts. His overall attitude to Freud was not unlike Hitchcock's: he was charmed - but ultimately not fooled - by it. In a letter to his friend and one-time pupil Norman Malcolm (written, incidentally, while Spellbound was in production), Wittgenstein explains:

I, too, was greatly impressed when I first read Freud. He's extraordinary. - Of course he is full of fishy thinking \& his charm \& the charm of the subject is so great that you may be easily fooled. He always stresses what great forces in the mind, what strong prejudices work against the idea of psychoanalysis. But he never says what an enormous charm that idea has for people, just as it had for Freud himself. There may be strong prejudices against uncovering something nasty, but sometimes it is infinitely more attractive than it is repulsive. Unless you think very clearly psycho-analysis is a dangerous \& foul practice, \& it's done no end of harm \&, comparatively, very little good. (If you think I'm an old spinster - think again!) - All this, of course, doesn't detract from Freud's scientific achievement. Only, extraordinary scientific achievements have a way these days, of being used for the destruction of human beings (I mean their bodies, or their souls, or their intelligence). So hold onto your brains ${ }^{40}$.

What does it mean for an impulse to be unconscious? What might a conscious impulse be like? And what does it mean to say that a memory is unconscious, or worse, that it resides in the unconscious? Such are the questions which interest the

39 Cf. Atkinson et. al (1990:517).

40 December 1945 (reproduced in Malcolm 1958: 44-5). 
philosopher of psychology, and Wittgenstein came to the conclusion that Freud's concepts are empty: they are without meaning. In so doing, he offered a different kind of therapy altogether: a cure from the bewitchment of language, which Freud himself seemed to be in great need of.

Consider the Freudian method of dream interpretation appealed to in both Spellbound and Marnie. This relies on the assumption that dreams have significance or meaning. But what exactly are we ascribing to them here? In ordinary language these terms are multiply ambiguous. The philosopher Paul Grice (1957) distinguishes between two importantly different senses in which we can use the term 'meaning' which may help us to elucidate things a little. He calls meaning understood in the first sense natural meaning, and contrasts it with what he calls non-natural meaning, which in turn divides into speaker meaning and expression meaning (cf. fn. 40 below). Claim (a) below uses 'mean' in what Grice calls a natural sense viz. meaning as indication:

(a) 'Those spots on your face mean you have measles'.

By contrast claim (b) below uses meaning in a non-natural sense:

(b) The French expression 'vous avez la rougeole' means 'you have measles'.

The crucial difference is that (a) is true in virtue of causal our natural relations (in the sense in which we say that 'clouds mean rain') where are (b) is true in virtue of linguistic and/or semantic conventions ${ }^{41}$.

Given that dreams - like clouds and unlike sentences - are not linguistic entities, it is sensible to suppose that we can only embed them with natural meaning. At times, Freud does just this:

A friend who was acquainted with my theory of dreams, and had explained it to his wife, said to me one day: "My wife asked me to tell you that she dreamt yesterday that she was having her menses. You will know what that means.' Of course I know: if the young wife dreams that she is having her menses, the menses have stopped. I can well imagine that she

${ }^{41}$ Accordingly, (b) is a case of expression meaning. Had he said that by 'vous avez la rougeole' Pierre actually means 'you have chickenpox' and not 'you have measles' it would be a case of speaker meaning, though it is of course possible for speakers to mean the right thing by an expression (indeed we cannot use expressions to simply mean whatever we wish at will cf. Wittgenstein, $1953 \S 510$. 
would have liked to enjoy her freedom a little longer, before the discomforts of maternity began. It was a clever way of giving notice of her first pregnancy 42 .

In the above anecdote the dream indicates that the woman was pregnant in the same way that the presence of clouds might indicate that it is going to rain (or the number of rings on the bark of a tree indicate how old the tree is without being semantic representations). So interpreted, its meaning is natural. Freud also takes the dream to be an expression of a wish fulfilment: she dreams of having menses because she wishes she could enjoy her freedom a little longer. This too can be understood naturally: the dream merely indicating that she must have such a wish (since we often dream of things we wish for and to dream of menses is to indirectly dream of being free since the one typically entails the other).

So far so natural, but Freud goes considerably further than this. He says the dream represents a wish as fulfilled ${ }^{43}$. Representation, however, requires symbol and something can only be a symbol if we intend to use it as such (the rings on the tree bark are a sign of how old the tree is but they do not symbolise its age). The dream, then, doesn't only signify something naturally, for it has now also been turned into a vehicle of intentional communication. So, in addition to his friend's statement about the dream (which is intended to communicate that his wife was pregnant ${ }^{44}$ ) we are told that the dream itself is used to communicate something, namely that its bearer has a certain wish. But this is to turn the dream into a symbol i.e. a pictorial representation, thereby embedding it with non-natural meaning (symbols are semantic entities and therefore-for all intents and purposes - would also count as linguistic entities for Grice).

There is nothing in principle wrong with the notion of one and the same thing having both natural and non-natural meaning. The words 'The End', for example, when they appear at the end of a motion picture are used to convey a certain message to the audience and in this respect have non-natural meaning. But a person completely ignorant of both this convention and the English language could and indeed typically would, having observed a certain number of films (on some views even just one or two), come to infer that when these 'squiggles' appear on the wall this

42 The Interpretation of Dreams (1900: Ch. 3, p.38), included in Freud (1953-74).

43 Ibid.

${ }^{44}$ This is why we need to be told that the friend is acquainted with Freud's theory of dreams. The number of such perfectly suited examples in Freud are so numerous that it is all-too-tempting to think he must have tailored them to fit his purposes, just as he does his terminology. 
means that the audience members will slowly start to rise from their seats and leave the cinema theatre. In this context the projected letters signify something nonnaturally (i.e. they do not do so by being treated as symbols; though it is true that their predictive use is parasitic upon their symbolic nature the person making the prediction need not know this ${ }^{45}$ ).

The problem with Freud's move towards non-natural meaning lies elsewhere, namely in the fact that non-natural meaning requires intention and/or community-wide convention ${ }^{46}$. But who is doing the intending (that is trying to tell us something) here? It cannot be the dreamer for the whole point of the theory is that she is unaware of her own wishes (which are unconscious). Freud rejects as worthless those 'primitive' answers to this question which either (i) only allow for the intuitive interpretation of dreams by soothsayers and prophets in trance or (ii) postulate a universal dream cipher (such that we might in principle be able to establish general key to the secret language of dreams which we could then transcribe into a dream dictionary for future consultation ${ }^{47}$ ). Instead, he applies his theory of divided personality (outlined in $\S 2$ above) which ascribes beliefs, aims, desires, goals, purposes, and intentions to the id, ego, and super-ego. In this particular case the id is trying to tell us something that the super-ego wishes to censor ${ }^{48}$.

This conception of the mind, however embodies what has come to be known as the homunculus fallacy ${ }^{49}$ viz. that fallacy of explaining how a sub-part of a person works in terms that are only applicable to the person as a whole (as if it contained a little man or 'homunculus') ${ }^{50}$. Freud does not address this problem, trading instead on the ambiguity of terms like 'meaning', 'value', 'importance' and 'significance' (which Grice's conceptual clarification would come to disambiguate).

Wittgenstein's criticism of Freud is that his fundamental theory relies upon the constant misapplication of psychological predicates. While he recognised the metaphorical power of Freud's views, he did so without falling into the trap of

\footnotetext{
45 Analogously, one might think that the gods 'mark' the trees age each year with a new circle. 46 Note that I am not here appealing to the details of Grice's particular account (indeed I think these should be rejected for broadly Wittgensteinian reasons).

47 Op. cit: Ch, 2. Alas such books 'of dreams' remain all too popular.

48 Indeed in his early work early work the roles played by the ego and super-ego are more crudely attributed to 'the censor'.

${ }^{49}$ Cf. Bouveresse (1995:39).

50 We might therefore characterize the homunculus fallacy as a special instance of the mereological (part-whole) fallacy criticized in Bennett \& Hacker (2003:68ff.)
} 
thinking that the metaphors can be cashed out without any theoretical loss ${ }^{51}$.Yet he was also astute enough to notice that a flawed scientific theory may nonetheless constitute not only an aesthetic achievement, but a scientific one too. Indeed the history of science is replete with muddled or mistaken theories that nonetheless produced results which would forever change the daily life of humans (Newton's now outdated theories are an obvious case in point). ${ }^{52}$

Likewise, Hitch was never one to throw the baby out with the bathwater. His Freudian Trilogy succeeds only because he is able keep psychoanalytic theory at a distance from where he can mock it yet simultaneously recognise its enormous pull, power, and achievement. It is because of this recognition that the trilogy continues to fascinate us while a film like The Seventh Veil, for its their cinematic achievement, provokes little to no contemporary debate. We might even go as far as to say that Hitchcock's Trilogy than Freud's own works.

\section{References}

Atkinson, R.L., Atkinson R.C., Smith, E.E., Beb, D.J., \& Hilgard, E.R. (1990), (eds.) Introduction to Psychology, 10 th edition (Florida: Harcourt Brace).

Ayer, A.J. (1936), Language, Truth, and Logic (London: Penguin).

Bader, D.M. (2005), One Hundred Great Books in Haiku (London: Viking Press).

Beeding, F. (1927), The House of Dr. Edwardes (London: Hodder \& Stoughton).

Bernays, E.L. (1928), Propaganda (NY: H. Liveright).

(1945), Public Relations (MA: Bellman Publishing Company).

51 Cf. Bennett \& Hacker (2003:80ff.) for the perils of using metaphors in the philosophy of mind more generally. Arto Laitinen reminded that the modern tendency towards neuropsychoanalysis attempts to save scientific face through the neurological reduction of the mind. It might thus be criticized for assuming a crude isomorphic form of representationalism (cf. Bennett \& Hacker 2003:111).

52 Cf. Kuhn 1962. Freud's nephew Edward Bernays employed flawed psychological theories in politics and public relations with instrumental success (cf. Bernays: 1928 \& 1945). Vance Packard would later do the same for marketing (Panckard:1957). For a critical assessment of the motivational theories employed see Sandis (2010). 
Bennet, M. R. and Hacker, P.M.S. (2003), Philosophical Foundations of Neuroscience (Oxford: Blackwell).

Bloch, R. (1959), Psycho (NY: Simon \& Schuster).

Brill, L. (2002), 'Spellbound: Love and Psychoanalysis', essay in Criterion Collection edition of Spellbound, 23 September.

Bouveresse, J. (1995), Wittgenstein Reads Freud - The Myth of the Unconscious, tr. C. Cosman (Princeton NJ: Princeton University Press).

Conrad, P. (2001), The Hitchcock Murders (London: Faber and Faber).

Dexter, G. (2007), Why Not Catch 21 ?: The Stories Behind the Titles (London: Frances Lincoln).

Freud, S. (1953-74), The Complete Works - The Standard Edition (24 Volumes including Introductory Lectures on Psychoanalysis, The Ego and the Id, The Interpretation of Dreams, and The Psychopathology of Everyday Life), ed. by James Strachey et al. (London: The Hogarth Press).

Godfrey-Smith, P. (2003) Theory and Reality: An Introduction to the Philosophy of Science (Chicago University Press, 2003 - New Edition).

Gottlieb, S. (2002), Framing Hitchcock: Selected Essays from the Hitchcock Annual (Detroit: Wayne State University Press).

(2003) (ed.), Alfred Hitchcock - Interviews (MS: University Press of Mississipi).

Grice, H.P. (1957), 'Meaning', The Philosophical Review, Vol. 66, No. 3. July, pp. 377-388.

Kuhn, T.S. (1962), The Structure of Scientific Revolutions (Chicago: University Press).

Leff, L. (2002), 'Selznik International's Spellbound', essay in Criterion Collection edition of Spellbound, 23 September.

Malcom, N. (1967) Wittgenstein: A Memoir (Oxford: Oxford University Press).

McGilligan, P. (2003), Alfred Hitchcock: A Life in Darkness and Light (New York \& London: Regan Books). 
Packard, V. (1957), The Hidden Persuaders (IN: Cardinal).

Popper, K. (1963), Conjectures and Refutations (London: Routledge and Kegan Paul).

Rebello, S. (1998) Alfred Hitchcock and the Making of Psycho (London: St. Martin's Griffin)

Robinson, R. (1960), 'An Interview with Alfred Hitchcock', Picture Parade, 5 June (BBC).

Sandis, C. (2010), The Things We do and Why We Do Them (Basingstoke: Palgrave Macmillan).

Spotto, D. (1983), The Dark Side of Genius: The Life of Alfred Hitchcock (London: Harper Collins).

Truffaut, F. (1967, 2nd edition 1985) Hitchcock (London: Simon \& Schuster).

Winston, G. (1961), Marnie (London: Hodder \& Stoughton).

Wittgenstein, L. (1953), Philosophical Investigations, tr. G.E.M. Anscombe (Oxford: Blackwell).

Wood, R. (2002), Hitchcock's Films Revisited (New York: Columbia University Press).

\section{About the author:}

Constantine Sandis is senior lecturer in philosophy at Oxford Brookes University \& NYU in London, and currently also a visiting fellow at the Helsinki Collegium for Advanced Studies. He works in the philosophy of action and its motivation, including the history of its ideas. Constantine is the editor of New Essays on the Explanation of Action (Palgrave Macmillan 2009), co-editor (with Timothy O' Connor) of A Companion to the Philosophy of Action (Wiley-Blackwell 2010), and The Things We do and Why We do Them (Palgrave Macmillan, 2010). He is currently working on an introduction to the philosophy of action (for Wiley-Blackwell) and co-editing (with Arto Laitinen) a book on Hegel on action.

Contact: csandis@brookes.ac.uk; c.sandis@nyu.edu 